\title{
Inhaler Devices in a Geriatric Patient Population: A Prospective Cross-Sectional Study on Patient Preferences
}

This article was published in the following Dove Press journal: Patient Preference and Adherence

\author{
Katharina Ruessel \\ Eva Luecke \\ Jens Schreiber \\ Department of Pneumonology, Otto-Von \\ -Guericke University, Magdeburg, \\ Germany
}

Purpose: The aim of this study was to examine the perception and preference of geriatric patients for commonly used inhaler devices in Germany.

Patients and Methods: This was a prospective, open-label cross-sectional study with inpatient inhaler-naïve geriatric volunteers (age $\geq 70$ years). All 106 participants were interviewed and subjected to a geriatric examination for cognitive, motor and fine motor skills before demonstrating the use of nine inhalers in random order. For each device, patients were asked to test the handling, to assess the device properties and to name the device that they would most or least prefer.

Results: The mean age of the patients was 80.8 years. From a selection of 7 predefined general inhaler attributes, ease of use, discrete handling and inhalation resistance were the most important for the geriatric participants. Across all inhaler devices, the volunteers needed an average of 2.47 attempts to error-free use. The device with the lowest mean number of attempts was the Nexthaler ${ }^{\circledR}(1.75 ; \mathrm{SD} \pm 0.903)$, followed by Spiromax ${ }^{\circledR}(1.96$; $\mathrm{SD} \pm 0.965)$ and Genuair $^{\mathbb{R}}(2.05 ; \mathrm{SD} \pm 1.027)$. There was a weak to moderate correlation between the number of attempts required to ensure the correct use of these three inhalers and the patient's cognitive and fine motor skills. Fifty-nine patients (56\%) chose the Nexthaler as the inhalation device that they would most prefer ( $p<0.001$ vs other devices). This was followed by Spiromax $(n=23 ; 22 \%)$ and Genuair $(n=12 ; 11 \%)$. The device that was least favored was the Elpenhaler ${ }^{\circledR}$ ( $p<0.001$ vs other devices).

Conclusion: Patient preference and frequency of inhaler handling-errors may vary between inhaler devices. The Nexthaler was the easiest-to-use and most popular device among inhaler-naïve patients.

Keywords: inhaler device handling, elderly, dementia, fine motor skills, inhaler errors, inhaler technique

\section{Introduction}

The emerging rise in Europe's elderly population is also accompanied by an increase in aging patients with obstructive pulmonary diseases. ${ }^{1,2}$ The Global Burden of Disease Study 2015 showed an increase in the prevalence of COPD of $44.2 \%$ and an increase in the mortality of $11.6 \%$ since 1990 worldwide. The prevalence of asthma increased by $12.6 \%$ in this period of time. These changes were mainly attributed to the aging population, whereas the age-standardized prevalence and mortality decreased for both diseases. ${ }^{3}$ These common disorders are associated with expanding morbidity and mortality in the elderly. ${ }^{4}$ Inhaled
Department of Pneumonology, Otto-VonGuericke University, Leipziger Strasse 44, Magdeburg 39120, Germany

$\mathrm{Tel}+4939 \mid 67$ I542I

Fax +493916713356

Email jens.schreiber@med.ovgu.de
Patient Preference and Adherence 2020:14 I8II-1822 
therapies are the cornerstone of pharmacological management for obstructive pulmonary diseases. ${ }^{5,6}$ Although evidence from randomized controlled studies suggests that all inhaler types could be equally efficacious, each inhaler displays distinct operating characteristics, and a good inhaler technique is critical to achieving optimal treatment effects. $^{7-10}$ Poor inhaler technique may vary between devices and has been associated with suboptimal drug delivery, increased adverse events and, consequently, poor adherence and/or impaired disease control. ${ }^{11-13}$ Tailoring the selection of the inhaler device to the individual patient is therefore an important aspect in clinical practice. $^{5,11,14}$

Three main types of inhaler devices are available: the pressurized metered dose inhaler (pMDI), the dry powder inhaler (DPI), and the soft mist inhaler (SMI). ${ }^{15}$ They are used to deliver medications, and therapeutic benefit depends on proper inhalation technique and sufficient deposition of the drug in all regions of the lungs, including the peripheral lung area. ${ }^{12,16}$ For example, the correct inspiration technique for a pMDI requires a slow deep breath, while a DPI device requires a faster initial breath. The correct technique is thus device-specific. ${ }^{17,18}$ Moreover, the correct technique involves specific maneuvers in the case of pMDI where shaking the inhaler has been demonstrated as being crucial in order to obtain an efficient emitted dose of the drugs. ${ }^{19}$ Multiple factors may influence the ability to use an inhaler device properly, such as device factors (device type and complexity of use), patient factors (eg, cognitive function, visual performance, hand and finger force, fine motor skills, and patient preference) and proper education of patients in device use. ${ }^{2,20}$ These issues are particularly relevant to consider when prescribing inhaler devices for older adults. ${ }^{20,21}$ Physical and cognitive impairments, which are common in elderly patients, pose special challenges to the correct use of inhaler devices. ${ }^{20}$ If these challenges were not addressed, $41 \%$ to $60 \%$ of patients used their inhaler inappropriately, which was accompanied by a non-adherence rate of at least $51 \%{ }^{22}$ Therapeutic success of inhalation therapy depends not only on the correct inhalation technique but also on the patient's perception, preference and satisfaction with the inhaler device. ${ }^{9,11}$ Multiple factors determine the patient's preference for an inhaler, and understanding these factors is critical to improve adherence and, hence, the treatment results. ${ }^{6,9,23}$ Accordingly, suboptimal adherence was associated with poor results in patients with asthma or COPD. ${ }^{9}$
To our knowledge, there are so far no industryindependent studies in Germany on how the practicability of inhalation devices is perceived by older people and which properties are most important for an inhaler in this age group. Choosing the appropriate inhaler device is expected to improve the success of inhaler technique, adherence to treatment and disease outcome in elderly patients. However, reviews comparing inhaler device preferences and techniques across older adults are scarce. ${ }^{24}$ The biggest drawback of all previous device preference research is that they were initiated by the companies that produce this device.

The aim of our study was to find out which devices are favored in an inhaler-naïve geriatric population and what influence cognitive and physical limitations have on patient preference. We also wanted to identify properties of inhalers that older patients rate as particularly important.

\section{Patients and Methods}

The primary objective of this industry-independent study was to examine geriatric patients' preference for commonly used inhaler devices in Germany. Secondary objectives included a) investigating inhaler device properties that are important to geriatric patients and b) evaluating error rates in the inhalation technique for different devices. Further objectives were to find out if the preference for an inhaler or errors in the inhalation technique correlate with demographic and other patient-specific parameters (eg, cognition, motor and fine motor skills).

\section{Study Design and Ethical Approval}

This was a prospective, open-label and industryindependent cross-sectional study of volunteer, inhalernaïve geriatric patients aged $\geq 70$ years. Study participants were recruited from the Department of Pneumonology of the Otto-von-Guericke University Magdeburg and the geriatric ward of the AMEOS Clinic in Stassfurt, Germany. The investigation period ran from August 2017 to January 2018.

The geriatric volunteers were interviewed face-to-face, a complete geriatric assessment was performed and for each patient, the following nine devices that did not contain any drug (placebo inhalers) were tested in random order:

- Dry-powder inhalers (DPIs): Breezhaler ${ }^{\circledR}$, Diskus ${ }^{\circledR}$, Elpenhaler $^{\circledR}$, Genuair $^{\circledR}$, Nexthaler $^{\circledR}$, Spiromax $^{\circledR}$, Turbohaler $^{\circledR}$ 
- Pressurized metered-dose inhaler (pMDI)

A customary pMDI (Flutiform ${ }^{\circledR}$ pMDI) was used

- Soft mist inhaler (SMI): Respimat ${ }^{\circledR}$

All selected devices were approved products in Germany with a high market share. The study was conducted in accordance with the Declaration of Helsinki, ${ }^{25}$ and the study protocol was approved by the local Ethics Committee of the Otto-von-Guericke University Magdeburg, Germany (reference number 74/17).

\section{Patients and Study Procedure}

Our goal was to include geriatric patients who had not been pretreated with an inhaler and were therefore unbiased about the different types of devices. A geriatric database (GERDA system) was used to select the patients to be enrolled. With the information stored there, patients with proven obstructive lung diseases were sorted out in advance. Potential candidates were then addressed personally by the investigator to clarify their willingness to participate in the study. The investigator provided detailed information about the study and on data privacy, and obtained written informed consent from eligible patients, ie, of men and women aged $\geq 70$ years with at least two internal diseases. Exclusion criteria for participation in the study were: a) lack of written consent, b) physical restrictions such as hemiparesis or amputations or motor impairments that were incompatible with the use of an inhaler device.

\section{Data Collection and Geriatric Assessment}

The patient's characteristics (gender, age, main diagnosis for hospitalization, secondary diagnoses, highest school-leaving qualification) were recorded and a geriatric assessment was performed. This included evaluation of cognitive function, evidence of depressive disorders, visual acuity, hand and finger force, and fine motor skills, as these functions are essential for the proper use of an inhaler device.

Cognitive function among this elderly group of patients was checked with the Mini-Mental State Examination (MMSE), part of it were tests of orientation, attention, memory, language and visual-spatial skills. ${ }^{26-28}$ The short form of the Geriatric Depression Scale (GDS-SF), an instrument consisting of 15 questions, was used to identify depressive disorders. ${ }^{29}$ Visual acuity (with and without glasses) was assessed with a near vision test.
Hand force measurement was then carried out using the model SH5001 dynamometer of the company SAEHAN corporation, Korea. The Saehan SH5005 Pinch Gauge was applied for finger force testing by evaluating pinch grip, three-point grip, and lateral grip. Individual's fine motor skills were checked using the Patterson Medical A8515 Jamar 9-Hole Peg Test Kit, USA. We matched the results of the hand and finger force measurements to the ageappropriate standard values specified by the SH5001 dynamometer and SH5005 Pinch Gauge manufacturer. The results of the 9-Hole Peg Test for fine motor skills were compared to age-matched norm values published by Mathiowetz et al in $1985 .^{30}$

\section{Inhaler Devices Evaluation}

All presented inhalers were placebo devices that did not contain any active agent and were intended for demonstration purposes only. Data for the evaluation of the nine devices were collected using a structured questionnaire developed on the basis of the Patient Satisfaction and Preference Questionnaire (PASAPQ) and the Feeling of Satisfaction with Inhaler (FSI-10) questionnaire. ${ }^{31,32}$ First, geriatric patients were asked to assess the importance of predefined attributes of inhaler devices in general, eg, color, design, discreet handling, easy handling, inhalation resistance, duration of inhalation, and dose counter. Ratings were reported on a Likert scale, ranging from 1 (very important) to 4 (unimportant).

Via a pregenerated randomization list, the investigator then demonstrated in randomized order how to use each of the nine inhaler devices. The handling of the individual devices was presented on the basis of standardized checklists for correct use, which had been developed by a panel of German expert pulmonologists. ${ }^{33,34}$ For each device, they included three major steps of inhalation: 1) inhalation preparation, 2) inhalation routine, and 3) closure of inhalation. ${ }^{33,34}$ Patients were asked to repeat the correct procedure after each demonstration. In the event of inhaler handling errors, use was again demonstrated by the investigator and repeated by the patient until the inhaler was used correctly. The investigator documented the number of attempts that the patient needed for the correct use. To assess the correct inhalation technique, standardized checklists were used again. ${ }^{33,34}$

After an inhaler device was presented by the investigator and subsequently tested by the patient, the participants were asked to rate device-related handling features. The following statements were to be evaluated for this purpose: "I like the 
design of the device", "It was easy to learn how to use the device", "It was easy to prepare the device", "The device is comfortable when held in my hand", "The mouthpiece was comfortable when using the device", "It was easy to use the device", "I felt that I had used the device correctly", "I think it is possible to use the device easily and correctly in emergency situations', and "Overall rating". The questions were measured on a Likert scale with possible answers 1 "applies perfectly", 2 "rather applies", 3 "partially true", 4 "rather not true", and 5 "not correct at all". After demonstrating all the devices, patients were finally asked to decide which of the nine devices they would most and which least prefer for daily use.

All face-to-face interviews, testing and device demonstration were conducted by the same person to avoid misjudgment by different investigators. The duration of the survey, including device demonstrations, was approximately 60 mins per patient.

\section{Statistical Analysis}

The data were stored electronically. We performed all data analysis using Microsoft Excel 2016 MSO (version 16.0.7329.1017) and WinSTAT for Microsoft Excel (version 2012.1.0.94). Primary and secondary objectives were analyzed using descriptive statistics. Continuous variables were described by means of standard statistical measures: number of observations, mean, standard deviation, median, minimum and maximum values, and number of missing values. Categorical variables were summarized with absolute and relative frequencies. Analyses of secondary objectives also included inferential statistics.

The Pearson's chi-squared test was used for sets of categorical data to test if the distribution of variables differed significantly from the average distribution. A p-value $<0.05$ was considered to be statistically significant. Nonparametric statistical tests for the continuous data included the Kruskal Wallis test for independent samples and the Friedman test for related samples. Spearman's Rank correlation (Spearman's Rho) was applied to summarize the strength and direction (negative or positive) of a relationship between paired data.

\section{Results}

\section{Patient Characteristics}

One hundred and six geriatric patients were recruited from the Department of Pneumology of the Otto-von-Guericke University Magdeburg and the geriatric ward of the
AMEOS Clinic in Stassfurt during the period from August 2017 to January 2018. The mean age of the participants was 80.8 years (standard deviation, SD: 6.3; 95\% confidence interval, CI: 79.5-82.0; minimum, $\min 70$, maximum, max 96), and $62.3 \%$ were female. Most common causes of hospitalization included trauma $(n=44)$, frailty $(n=35)$, congestive heart failure $(n=14)$, and pain $(n=5)$. Other main diagnoses for hospitalization were exsiccosis $(n=3)$, delirium $(n=2)$, hypertensive crisis $(n=1)$, neurological disorders $(n=1)$, and deterioration of general condition $(n=1)$. Four patients had newly diagnosed COPD as a secondary diagnosis, and another two were suspected to have COPD, but these patients were inhaler naïve as well.

\section{Geriatric Examination}

The results for hand strength and visual acuity (if applicable with glasses) turned out to be in the age-appropriate normal range. The finger force measurements showed slightly below average values and the results of the fine motor skills measurements were slightly above average (Table 1). The median was 25.5 ( $\min 0$, $\max 30$ ). Analyses of the geriatric depression scale (GDS-15) showed a mean ( \pm SD) of 4.83 (3.33). The median was 4.00 (min. 0, max. 13). A GDS-15 score $>5$ is indicative of depression. The Mini-Mental State Examination (MMSE) for the detection of cognitive impairments resulted in a mean $( \pm \mathrm{SD})$ of 23.98 (5.16), which corresponded to mild dementia. A total of $46(43.4 \%)$ patients showed normal cognition (MMSE score of 27 or better), 42 (39.6\%) patients had mild dementia (MMSE score of 20-26) and $18(17.0 \%)$ patients had moderate dementia (MMSE score of 10-19 points).

\section{Inhaler Devices Assessment}

When asked about the relevance of predefined inhaler attributes ("Which properties of an inhaler are important to you?"), the patients stated the following in descending order of importance: easy handling, discreet handling, inhalation resistance, duration of inhalation, dose counter, design, and color. Figure 1 shows the proportion of patients who rated the respective inhaler attributes as "very important", "important", "less important" or "unimportant".

Across all devices, patients needed an average of 2.47 attempts to use the inhaler correctly (women: 2.57; men: 2.32). The number of attempts required for the correct use of the device differed significantly between the nine placebo inhalers $(\mathrm{p}<0.001)$. The device with the lowest mean error 
Table I Test Results from the Geriatric Assessment of Visual Acuity, Hand Force, Finger Force, and Fine Motor Skills

\begin{tabular}{|l|l|l|l|l|l|l|}
\hline & N & Mean & SD & Median & Min & Max \\
\hline Visual acuity with glasses & 106 & 0.460 & 0.2707 & 0.500 & 0.0 & 1.0 \\
Visual acuity without glasses & 106 & 0.081 & 0.1908 & 0.000 & 0.0 & 0.7 \\
Hand force left & 106 & 17.0708 & 8.48475 & 16.3333 & 0.00 & 41.33 \\
Hand force right & 106 & 18.7264 & 8.33480 & 18.0833 & 0.00 & 40.67 \\
Pinch grip right & 106 & 4.7189 & 1.93593 & 4.6500 & 0.00 & 11.00 \\
Three-point grip right & 106 & 5.2151 & 2.06756 & 5.4000 & 0.00 & 10.00 \\
Lateral grip right & 106 & 5.8991 & 2.11721 & 5.9500 & 0.00 & 10.50 \\
Pinch grip left & 106 & 4.5519 & 2.05525 & 4.5000 & 0.00 & 9.00 \\
Three-point grip left & 106 & 4.9066 & 2.05075 & 5.1500 & 0.00 & \\
Lateral grip left & 106 & 5.3708 & 2.15570 & 5.5000 & & 0.00 \\
9-Hole Peg Test & 106 & 28.3542 & 11.85034 & 24.6150 & 17.50 & 11.00 \\
\hline
\end{tabular}

Abbreviations: Max, maximum; Min, minimum; N, number; SD, standard deviation.

rate was the Nexthaler (1.75; $\mathrm{SD} \pm 0.903)$, followed by Spiromax (1.96; SD \pm 0.965$)$ and Genuair $(2.05 ; \pm 1.027)$ (Figure 2). The randomization order in which the nine devices were demonstrated and tested had no relevant influence on the number of attempts until error-free use (Figure $3 \mathrm{~A}$ and $\mathrm{B}$ ). Statistical tests showed weak to moderate correlations between the number of attempts required to ensure the correct use and the patient's cognitive and fine motor skills. For the three devices with the lowest error rates, the number of attempts until the inhaler was used correctly and the cognitive function or fine motor skills showed the following correlation coefficients (Spearman-Rho): $r=-0.440$ (cognitive function; $\mathrm{p}<0.001$ ) and $\mathrm{r}=-0.346$ (fine motor skills; $\mathrm{p}<0.001)$ for Nexthaler; $\mathrm{r}=-0.323(\mathrm{p}=0.001)$ and $\mathrm{r}=-0.315$ $(p=0.001)$ for Spiromax; $r=-0.463(p<0.001)$ and $r=0.457$ $(p<0.001)$ for Genuair. Only with the Spiromax inhaler did the hand and finger force influence the number of attempts required for the correct use of the device (left-hand grip force: $\mathrm{p}=0.013$; left 3-point grip: $\mathrm{p}=0.014$ ).

Figure 6 shows for each of the nine devices how geriatric patients assessed the ease of use and other features of device handling. After the demonstration and selftesting of all inhaler devices, $56 \%$ of the patients chose the Nexthaler as the inhalation device that they would most prefer ( $<<0.001$ vs other devices; Figure 4). Spiromax and Genuair ranked second and third, respectively. The three most favored devices were also the inhalers for which participants needed the least number of attempts until error-free use (Figure 2). The least preferred device was the Elpenhaler $(\mathrm{p}<0.001$ vs other devices; Figure 5). For the three top-ranked devices, there was a dependency of positive preference on cognitive status as determined by

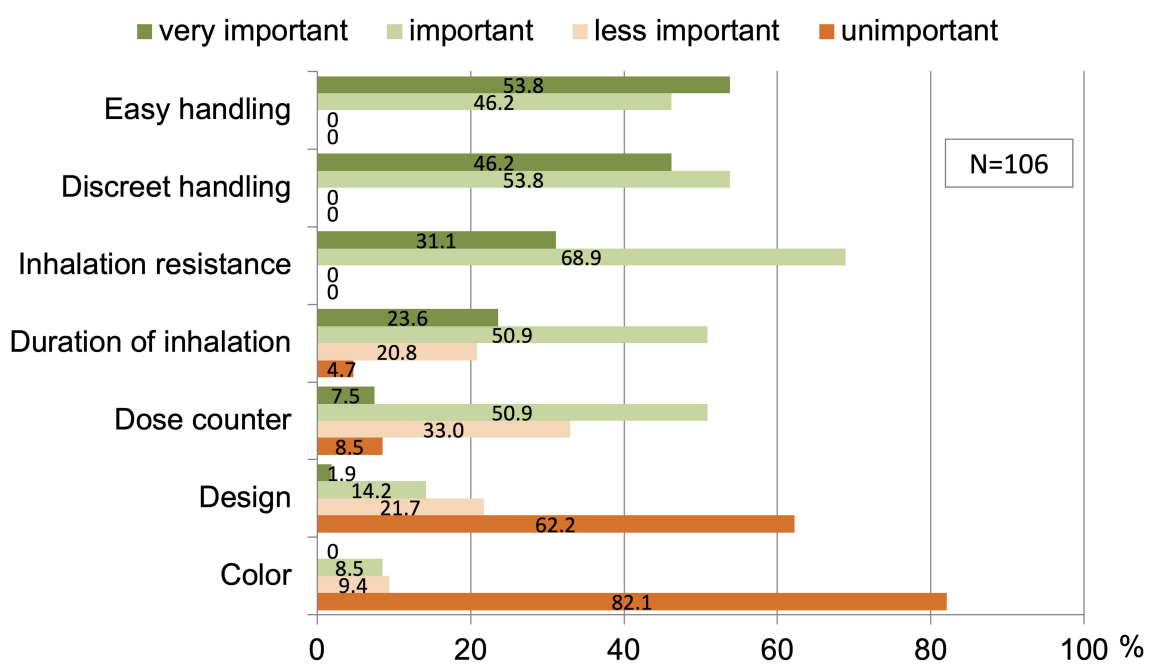

Figure I Importance of inhaler attributes from the perspective of geriatric patients $(\mathrm{N}=106)$. Proportion of patients (\%) who gave the respective rating. Abbreviation: N, patient number. 


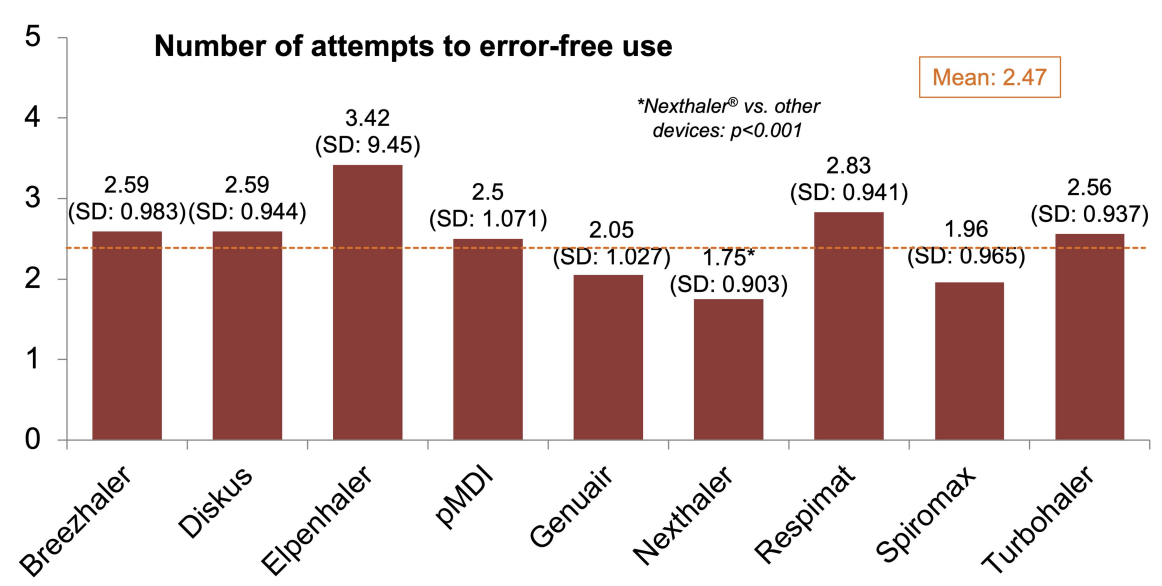

Figure 2 Number of attempts (mean) that patients needed until the inhaler device was used correctly. The dotted line shows the mean of attempts to error-free use across all 9 devices (2.47). *Nexthaler vs other devices $p<0.001$.

Abbreviations: SD, standard deviation; vs, versus.
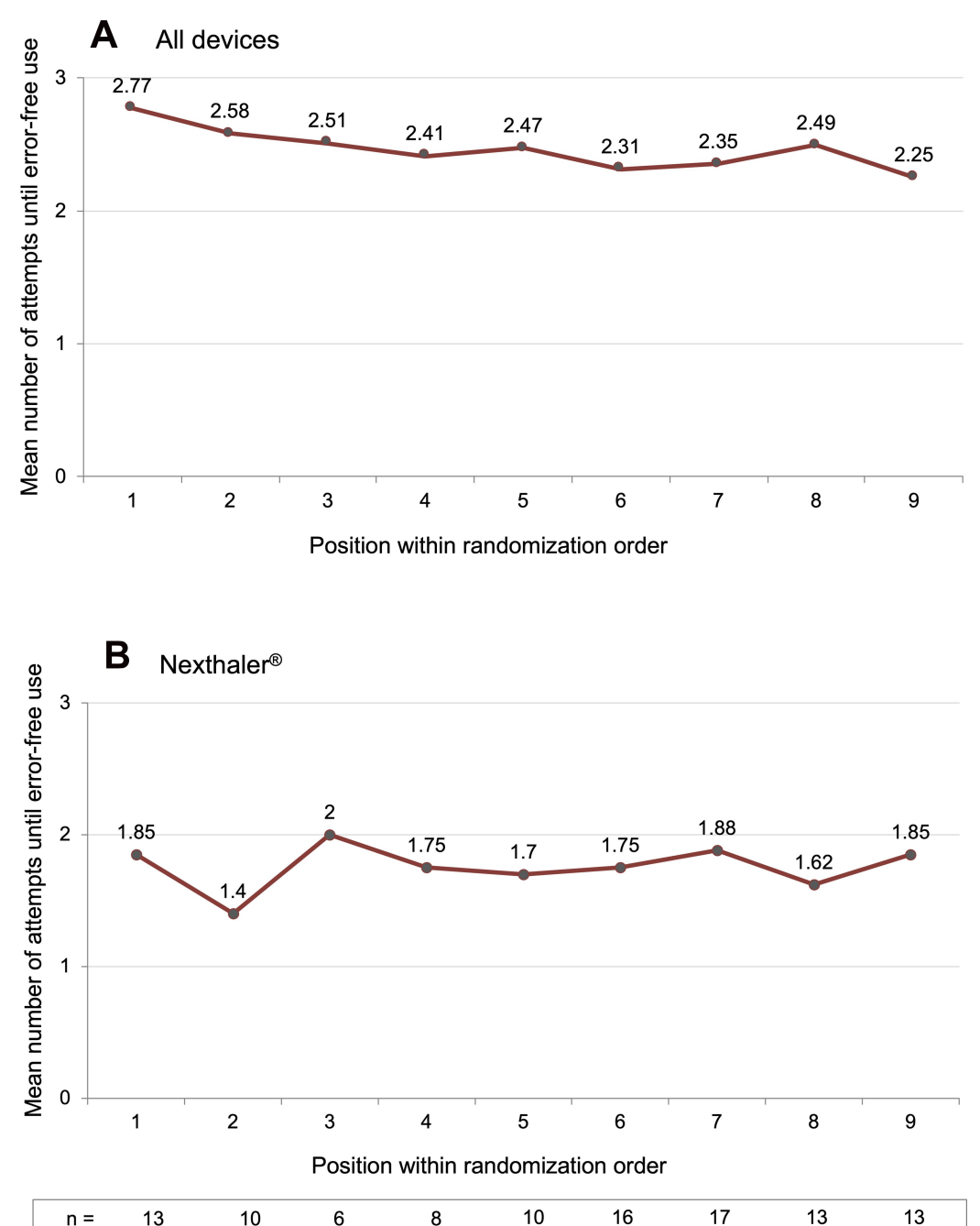

Figure 3 Average number of attempts until the inhaler was used correctly by the patients $(\mathrm{N}=106)$ depending on the position within the randomization sequence for device demonstration and testing (A) across all devices, (B) for the Nexthaler. The dotted line shows the mean of attempts to error-free use across all 9 devices (2.47). Abbreviation: $N / n$, number of patients. 


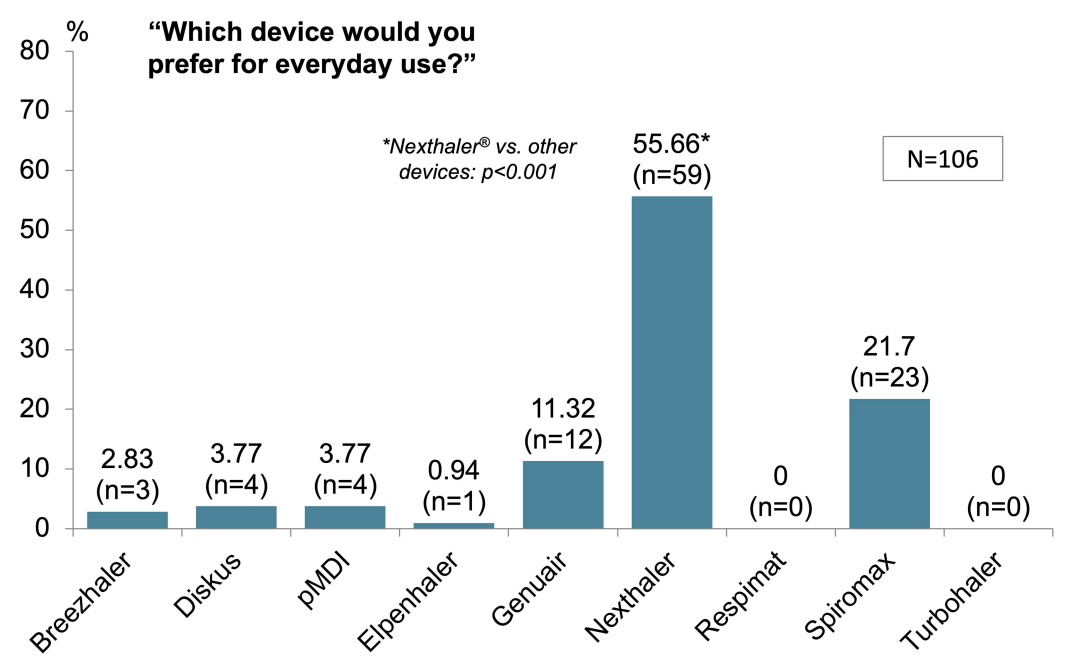

Figure 4 Positive preference: device that patients $(\mathrm{N}=106)$ would choose from amongst the 9 featured inhalers. Proportion of patients (\%) who reported a positive preference for the respective device. Each patient was allowed to name only one device preference.

Abbreviation: $\mathrm{N} / \mathrm{n}$, patient number.

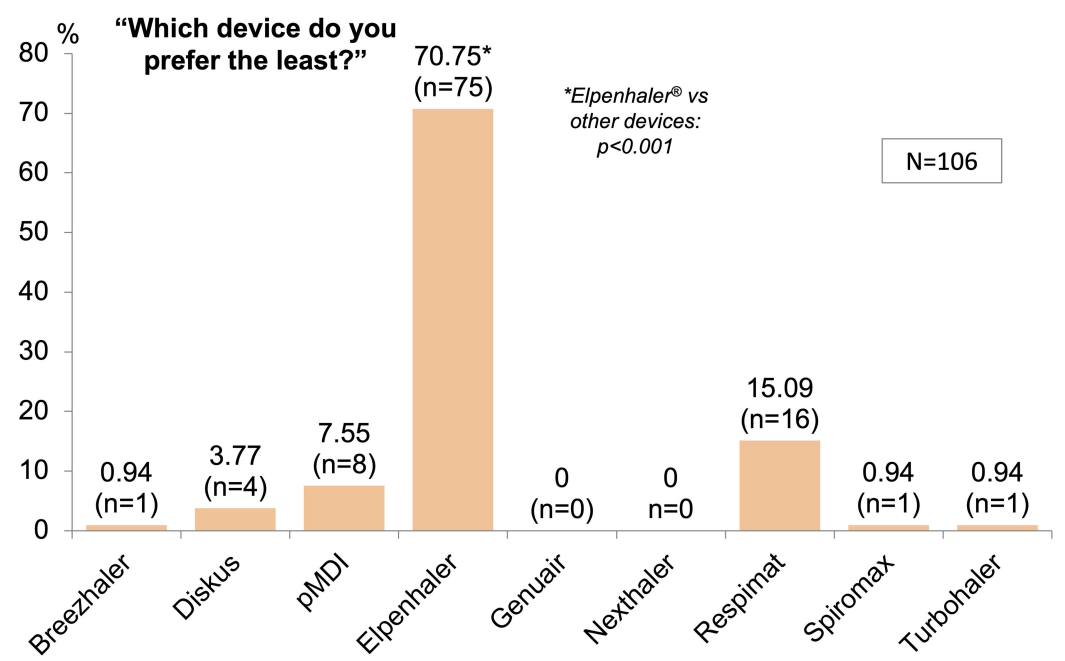

Figure 5 Negative preference: device that patients $(\mathrm{N}=106)$ would least prefer among the 9 inhalers presented. Percentage of patients $(\%)$ who reported a negative preference for the respective device. Each patient was allowed to name only one negative preference. * Elpenhaler vs other devices: $\mathrm{p}<0.00 \mathrm{I}$.

Abbreviations: $N / n$, patient number; vs, versus.

MMSE ( $\mathrm{p}=0.004$, Figure 7). Patients who preferred the Nexthaler had less hand and finger strength compared to patients who preferred Spiromax (right-hand grip force: $\mathrm{p}=0.010$; left 3-point grip: 0.021 ; right lateral grip: $\mathrm{p}=0.008$; left lateral grip: $\mathrm{p}=0.014)$. In this geriatric population ( $\geq 70$ years of age), positive preference for a device was not influenced by age, gender or education (highest school-leaving qualification).

\section{Discussion}

When choosing suitable inhalers for geriatric patients, the patient's specific needs, physical and cognitive abilities and preferences should be taken into account, ${ }^{22}$ for matching the patients to the device that is the most appropriate for them. ${ }^{35-37}$ In respiratory disorders, patient-perceived satisfaction with the inhaler device is an important factor driving treatment adherence and outcomes. ${ }^{11,23,38}$ Findings from other studies confirm that important differences exist between inhaler devices, which could have implications for disease control when selecting a device for a patient. ${ }^{39}$ A patient's ability to use an inhaler correctly and their preference for the inhaler are both important factors in selecting an appropriate treatment for obstructive pulmonary diseases. ${ }^{40}$ Each type of inhaler device is associated with advantages and limitations that determine their suitability for any given patient with asthma or COPD. Understanding those advantages and 


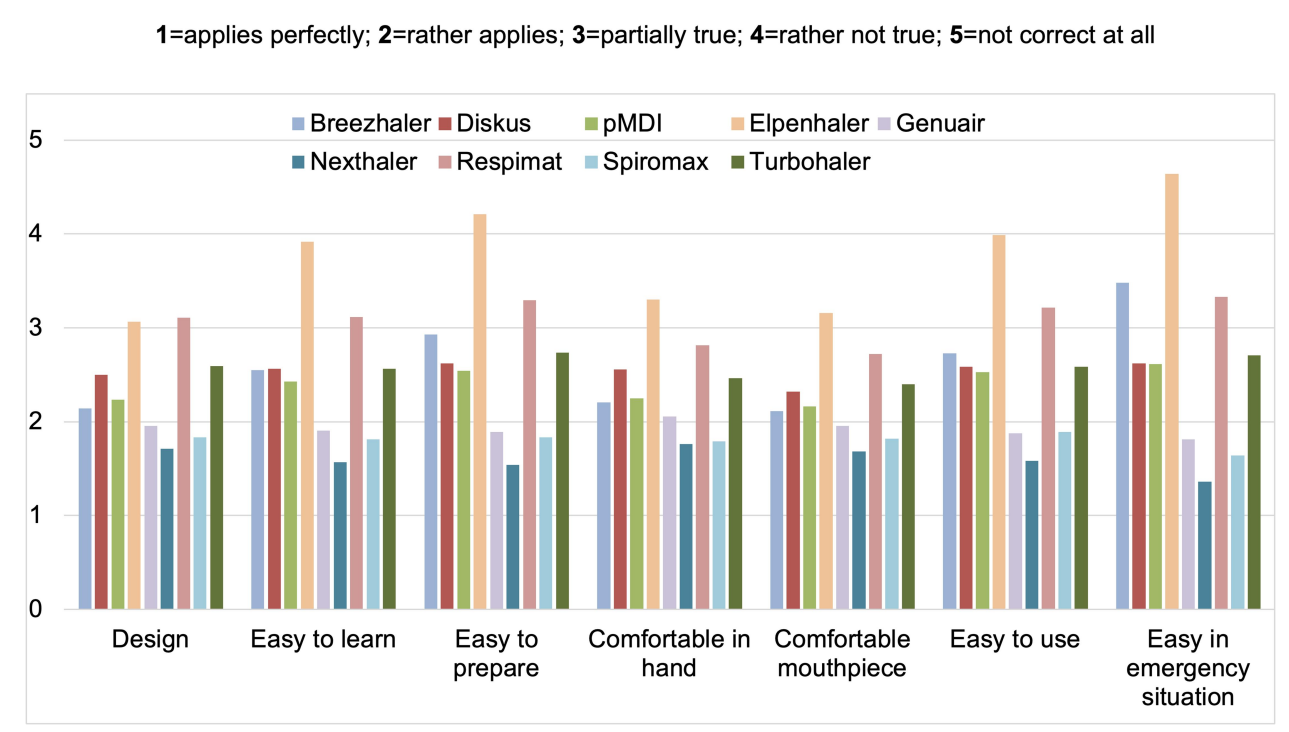

Figure 6 Device-related handling characteristics, assessed by the geriatric patients using "school grades" from I to 5 . Like the design = I like the design of the device. Easy to learn = It was easy to learn how to use the device. Easy to prepare = It was easy to prepare the device. Comfortable in hand = The device is comfortable when held in my hand. Comfortable mouthpiece $=$ The mouthpiece was comfortable when using the device. Easy to use $=$ It was easy to use the device. Correct use $=\mathrm{I}$ felt that I had used the device correctly. Easy in emergency situations $=\mathrm{I}$ think it is possible to use the device easily and correctly in emergency situations. $*$ Nexthaler vs other devices $\mathrm{p}<0.00 \mathrm{I}$.

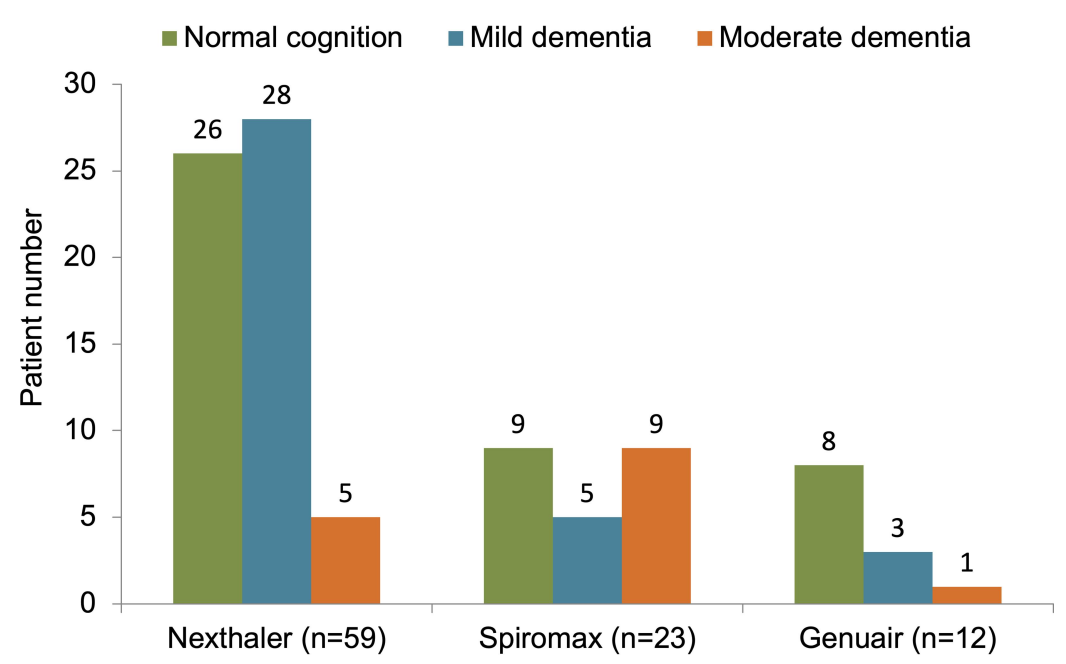

Figure 7 Dependency of positive preference on cognitive status: Comparison of the 3 inhalation devices that performed best, grouped in terms of cognitive status as assessed by MMSE. Spiromax was more frequently mentioned as the preferred device for moderate dementia, Nexthaler more often for mild dementia and Genuair for normal cognition ( $p=0.004$ for the difference in distribution). The dotted lines show the percentage of patients from the entire population ( $N=106)$ who were documented in the respective dementia category. Normal cognition = MMSE score of 27; mild dementia = MMSE score of 20-26; moderate dementia = MMSE score of I0-19 points. Abbreviations: MMSE, Minimal-Mental State Examination; N/n, patient number.

limitations may help clinicians in choosing the proper device for the individual patient's clinical needs and preferences. It is important to tailor the selection of the inhaler device to the individual patient, taking into account their needs and preferences. ${ }^{11}$ Research confirms that there are substantial differences in patient's preference and acceptability for inhalers, mainly related to the handling of the different devices. ${ }^{23}$ For patients, the most important attribute of an inhaler was that its instructions were easy and simple to follow. ${ }^{11}$
Naturally, the pharmacology of the inhaled substances is crucial and not all substance classes or combinations are available in all inhaler devices, what may restrict their application.

Our study examined a geriatric volunteer population that had no experience with inhaler devices. We analyzed the needs and preferences of older patients when using inhalers and how easy or difficult it is to use different devices correctly, also depending on the dementia status, 
hand and finger force, and fine motor skills in this age group. The following devices were tested: Breezhaler, Diskus, Elpenhaler, Genuair, Nexthaler, Spiromax, Turbohaler, a customary pMDI (Flutiform pMDI), and Respimat. To our best knowledge, this is the first industryindependent study in Germany to compare such a large number of different inhaler devices in a geriatric population. The Nexthaler performed best, both in terms of patient preference and the number of attempts until errorfree use of the inhaler. The device was preferred by more than half of the geriatric patients surveyed. Spiromax and Genuair followed in the further ranking. It should be kept in mind that there are further easy to use devices on the market, eg, the Ellipta-Inhaler, which were not included in our study. A study group in Japan evaluated the number of instructions that were necessary to minimize errors in using pMDI, SMI, and DPI in both patients with asthma and in patients with COPD $(\mathrm{N}=216)$. The authors concluded that it was necessary to repeat the instructions approximately three times in order to achieve effective inhalation skills. ${ }^{41}$ This coincides with our results, which gave an average number of attempts of 2.57 until errorfree use.

Device handling, correct inhaler technique, patient preference, and adherence are intertwined factors that may all contribute to good symptom control. ${ }^{39}$ Other studies confirm that devices with the lowest number of handling errors had the highest ratings in patient preferences, ${ }^{42}$ suggesting that a patient's acceptance of a device may be correlated with ease of handling. ${ }^{39}$ Chorao et al carried out a cross-sectional assessment of 301 adults in Portugal, with asthma or COPD, undergoing treatment with Aerolizer, Autohaler, Breezehaler, Diskus, Handihaler, pMDI without spacer, Miat-haler, Novolizer, Respimat and/or Turbohaler. Patients completed self-assessment questionnaires and face-to-face interview, with demonstration of the inhaler technique. The frequency of inhaler technique errors was high and no device was clearly preferred over the others. Contradicting to our results, using the preferred inhaler device was not associated with fewer errors. However, it should be noted that $74 \%$ of the patients in the study were younger than 65 years. ${ }^{43}$ Poor inhaler technique is evident in older adults. ${ }^{21}$ A systematic review compared pMDI and DPI techniques across elderly and younger cohorts to determine whether differences exist between such cohorts with regards to the number and type of device errors made. Evidence suggested a negative correlation between advancing age and correct technique across varying devices. ${ }^{24}$ However, this question is controversial: There are also studies in which no dependency of the frequency of device handling errors on age was observed. 5,41

There are a number of competing factors for the patient that affect device preferences and the technique of device use. ${ }^{8}$ For example, cognitive impairments can be an

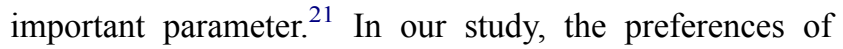
geriatric patients for an inhaler and the frequency of errors when using the devices showed a dependence on the cognitive status or, respectively, on the cognitive and fine motor skills of the participants. One possible explanation could be that patients with mild impairment only perceive their mistakes, what cause emotional discomfort, therefore they would prefer devices less prone to errors.

Above all, ease-of-use of an inhaler seems to markedly influence geriatric patients' preference for a device. ${ }^{22}$ Our results are consistent with the literature on this point. A study conducted in France assessed asthma and COPD patients' preferences for different attributes of DPIs. Here, as well, patients placed the highest values on attributes related to ease of use. ${ }^{9}$ Ding et al examined inhaler preferences in asthma and COPD from the patient's perspective, particularly focusing on the relative importance of individual device attributes and patient characteristics guiding inhaler choice. ${ }^{11}$ Instructions being "simple and easy to follow" was the inhaler attribute most commonly selected as important. ${ }^{11}$ In our geriatric collective, too, the easy handling of the inhaler played an important role in the choice of the preferred device. The three inhalers that were most favored also had the best ratings in terms of "ease of learning", "ease of preparing", "ease of holding", and "ease of operation".

A question that is often discussed regarding dry powder inhalers is whether DPIs are a suitable device for geriatric patients. Some doctors do not recommend DPI in their older patients, due to the rather complex operating steps. In addition, studies indicate that a large proportion of the elderly are unable to exert sufficient respiratory flow to deagglomerate the powder. ${ }^{44}$ The results of our study in a geriatric population, on the other hand, show that older people prefer dry powder inhalers over pMDI and SMI. DPI therefore seem to be well suited for geriatric patients, provided that there is sufficient inspiratory airflow.

\section{Limitations}

This was a prospective, open-label cross-sectional study that collected data from a sample of hospitalized and inhaler-naïve geriatric volunteers. The study offers 
valuable insight into eliciting possible patient preferences for inhaler devices in a geriatric population, taking into account mental and physical impairments. Nevertheless, the results should be interpreted within the context of study limitations. First, there may have been possible patient selection bias, as there are special prerequisites for geriatric inpatient treatment in the German healthcare system. These are patients, in whom a substantial improvement of their health status is likely as a result of the comprehensive geriatric treatment. Thus, these patients only partly represent the whole population of geriatric patients. Second, our study examined widely used, but not all, inhalers available on the German market. Third, the generalizability of our findings, in particular the transferability to non-hospitalized elderly patients with obstructive pulmonary diseases, can be limited, as we choose patients without respiratory compromise and without previous experience with inhaler devices. Forth, patientperceived satisfaction with the inhaler device is an important factor driving treatment adherence and outcomes. "Satisfaction" also depends on the effectiveness of treatment. The latter was not measured, but it might influence the preference. Fifth, the errors of use of the inhalers are not measured prospectively. Therefore, we cannot assess the persistency of the correct use in patients, which frequently suffer from memory impairment.

\section{Conclusion}

The selection of an appropriate inhaler device for elderly patients should be done with great care. Our industryindependent study of a geriatric population included inhalers that are widely used in Germany (Breezhaler, Diskus, Elpenhaler, a customary pMDI, Genuair, Nexthaler, Respimat, Spiromax and Turbohaler). The Nexthaler turned out to be the most popular device in this age group. Spiromax and Genuair followed in second and third places. Inhaler perception, patient preference and the frequency of inhaler handling-errors may vary between devices and are also affected by the patient's cognitive status and fine motor skills. These points should be kept in mind when prescribing an inhaler device for older adults. Choosing the most appropriate inhaler for a specific geriatric patient may promote better adherence to therapy with improved disease outcome.

\section{Abbreviation}

COPD, chronic obstructive pulmonary disease; DPI, drypowder inhaler; FSI-10, Feeling of Satisfaction with Inhaler questionnaire; GDS-SF, Geriatric Depression Scale
Short Form; max, maximum; min, minimum; MMSE, MiniMental State Examination; PASAPQ, Patient Satisfaction and Preference Questionnaire; pMDI pressurized metereddose inhaler; SD, standard deviation; vs, versus.

\section{Data Sharing Statement}

The datasets used and/or analyzed during the current study are available from the corresponding author in response to reasonable requests.

\section{Acknowledgments}

We would like to thank Anja Luetke (medinform, Ratekau, Germany) for editorial support.

\section{Disclosure}

The authors report no conflicts of interest in this work.

\section{References}

1. Rechel B, Grundy E, Robine JM, et al. Ageing in the European Union. Lancet. 2013;381(9874):1312-1322.

2. Barrons R, Pegram A, Borries A. Inhaler device selection: special considerations in elderly patients with chronic obstructive pulmonary disease. Am J Health Syst Pharm. 2011;68(13):1221-1232. doi:10.2146/ajhp100452

3. GBD 2015 Chronic Respiratory Disease Collaborators. Global, regional, and national deaths, prevalence, disability-adjusted life years, and years lived with disability for chronic obstructive pulmonary disease and asthma, 1990-2015: a systematic analysis for the Global Burden of Disease Study 2015. Lancet Respir Med. 2017;5 (9):691-706. doi:10.1016/S2213-2600(17)30293-X

4. Gupta P, O'Mahony MS. Potential adverse effects of bronchodilators in the treatment of airways obstruction in older people: recommendations for prescribing. Drugs Aging. 2008;25(5):415-443. doi:10.2165/00002512-200825050-00005

5. Melzer AC, Ghassemieh BJ, Gillespie SE, et al. Patient characteristics associated with poor inhaler technique among a cohort of patients with COPD. Respir Med. 2017;123:124-130. doi:10.1016/j. rmed.2016.12.011

6. Virchow JC, Crompton GK, Dal Negro R, et al. Importance of inhaler devices in the management of airway disease. Respir Med. 2008;102 (1):10-19. doi:10.1016/j.rmed.2007.07.031

7. Rogliani P, Calzetta L, Coppola A, et al. Optimizing drug delivery in COPD: the role of inhaler devices. Respir Med. 2017;124:6-14. doi:10.1016/j.rmed.2017.01.006

8. Price D, Fletcher M, van der Molen T. Asthma control and management in 8000 European patients: the REcognise Asthma and LInk to Symptoms and Experience (REALISE) survey. NPJ Prim Care Respir Med. 2014;24:14009. doi:10.1038/npjpcrm.2014.9

9. Hawken N, Torvinen S, Neine ME. Patient preferences for dry powder inhaler attributes in asthma and chronic obstructive pulmonary disease in France: a discrete choice experiment. BMC Pulm Med. 2017;17(1):99. doi:10.1186/s12890-017-0439-x

10. Scichilone N. Asthma control: the right inhaler for the right patient. Adv Ther. 2015;32(4):285-292. doi:10.1007/s12325-015-0201-9

11. Ding B, Small M, Scheffel G, Holmgren U. Maintenance inhaler preference, attribute importance, and satisfaction in prescribing physicians and patients with asthma, COPD, or asthma-COPD overlap syndrome consulting for routine care. Int J Chron Obstruct Pulmon Dis. 2018;13:927-936. doi:10.2147/COPD.S154525 
12. Melani AS, Bonavia M, Cilenti V, et al. Inhaler mishandling remains common in real life and is associated with reduced disease control. Respir Med. 2011;105(6):930-938. doi:10.1016/j.rmed.2011.01.005

13. Molimard M, Raherison C, Lignot S, et al. Chronic obstructive pulmonary disease exacerbation and inhaler device handling: real-life assessment of 2935 patients. Eur Respir J. 2017;49 (2):1601794. doi:10.1183/13993003.01794-2016

14. Usmani OS. Choosing the right inhaler for your asthma or COPD patient. Ther Clin Risk Manag. 2019;15:461-472. doi:10.2147/ TCRM.S160365

15. Stein SW, Thiel CG. The history of therapeutic aerosols: a chronological review. J Aerosol Med Pulm Drug Deliv. 2017;30 (1):20-41. doi:10.1089/jamp.2016.1297

16. Allen SC, Ragab S. Ability to learn inhaler technique in relation to cognitive scores and tests of praxis in old age. Postgrad Med J. 2002;78(915):37-39. doi:10.1136/pmj.78.915.37

17. Brocklebank D, Ram F, Wright J, et al. Comparison of the effectiveness of inhaler devices in asthma and chronic obstructive airways disease: a systematic review of the literature. Health Technol Assess. 2001;5(26):1-149. doi:10.3310/hta5260

18. Price D, Haughney J, Sims E, et al. Effectiveness of inhaler types for real-world asthma management: retrospective observational study using the GPRD. J Asthma Allergy. 2011;4:37-47.

19. Chierici V, Cavalieri L, Piraino A, et al. Consequences of not-shaking and shake-fire delays on the emitted dose of some commercial solution and suspension pressurized metered dose inhalers. Expert Opin Drug Del. 2020:1-15. doi:10.1080/17425247.2020.1767066.).

20. Lavorini F, Mannini C, Chellini E, Fontana GA. Optimising inhaled pharmacotherapy for elderly patients with chronic obstructive pulmonary disease: the importance of delivery devices. Drugs Aging. 2016;33(7):461-473. doi:10.1007/s40266-016-0377-y

21. Turan O, Turan PA, Mirici A. Parameters affecting inhalation therapy adherence in elderly patients with chronic obstructive lung disease and asthma. Geriatr Gerontol Int. 2017;17(6):999-1005. doi:10.1111/ ggi. 12823

22. Barrons R, Wheeler J, Woods JA. Opportunities for inhaler device selection in elderly patients with asthma or COPD. Patient Intell. 2015;7:53-65. doi:10.2147/PI.S61200

23. Dal Negro RW, Povero M. Acceptability and preference of three inhalation devices assessed by the Handling Questionnaire in asthma and COPD patients. Multidiscip Respir Med. 2016;11:7. doi:10.1186/ s40248-016-0044-5

24. Barbara S, Kritikos V, Bosnic-Anticevich S. Inhaler technique: does age matter? A systematic review. Eur Respir Rev. 2017;26 (146):170055. doi:10.1183/16000617.0055-2017

25. Association WM. World Medical Association Declaration of Helsinki: ethical principles for medical research involving human subjects. JAMA. 2013;310(20):2191-2194.

26. Folstein MF, Folstein SE, McHugh PR. "Mini-mental state" A practical method for grading the cognitive state of patients for the clinician. J Psychiatr Res. 1975;12(3):189-198. doi:10.1016/ 0022-3956(75)90026-6

27. Tombaugh TN, McIntyre NJ. The mini-mental state examination: a comprehensive review. J. Am Geriatr Soc. 1992;40(9):922-935. doi:10.1111/j.1532-5415.1992.tb01992.x

28. O’Bryant SE, Humphreys JD, Smith GE, et al. Detecting dementia with the mini-mental state examination in highly educated individuals. Arch Neurol. 2008;65(7):963-967. doi:10.1001/ archneur.65.7.963

29. Sheik J, Yesavage J. Geriatric Depression Scale (GDS): recent evidence and development of a shorter version. Clin Gerontol. 1986;5:165-172. doi:10.1300/J018v05n01_09
30. Mathiowetz V, Weber K, Kashman N, et al. Adult norms for the Nine Hole Peg Test of finger dexterity. OTJR: Occup Particip Health. 1985;5:24-38.

31. Kozma CM, Slaton TL, Monz BU, Hodder R, Reese PR. Development and validation of a patient satisfaction and preference questionnaire for inhalation devices. Treat Respir Med. 2005;4 (1):41-52. doi:10.2165/00151829-200504010-00005

32. Perpiñá Tordera M, Viejo JL, Sanchis J, et al. Assessment of patient satisfaction and preferences with inhalers in asthma with the FSI-10 Questionnaire. Arch Bronconeumol. 2008;44(7):346-352. doi:10.10 16/S0300-2896(08)70447-2

33. Knipel V, Schwarz S, Magnet FS, et al. Checklists for the assessment of correct inhalation therapy. Pneumologie. 2017;71(2):96-105. doi:10.1055/s-0042-121285

34. The Deutsche Atemwegsliga e.V. (German Airway League) [homepage on the Internet]. Correct Inhalation Technique; 2019. Available from: https://www.atemwegsliga.de/correct-inhalation.html. Accessed December 09, 2019.

35. Haughney J, Price D, Barnes NC, Virchow JC, Roche N, Chrystyn H. Choosing inhaler devices for people with asthma: current knowledge and outstanding research needs. Respir Med. 2010;104 (9):1237-1245. doi:10.1016/j.rmed.2010.04.012

36. Chrystyn H, Price D. Not all asthma inhalers are the same: factors to consider when prescribing an inhaler. Prim Care Respir J. 2009;18 (4):243-249. doi:10.4104/pcrj.2009.00029

37. Dekhuijzen PN, Vincken W, Virchow JC, et al. Prescription of inhalers in asthma and COPD: towards a rational, rapid and effective approach. Respir Med. 2013;107(12):1817-1821. doi:10.1016/j. rmed.2013.09.013

38. Darbà J, Ramírez G, Sicras A, Francoli P, Torvinen S, Sánchez-de la Rosa R. The importance of inhaler devices: the choice of inhaler device may lead to suboptimal adherence in COPD patients. Int J Chron Obstruct Pulmon Dis. 2015;10:2335-2345. doi:10.21 47/COPD.S90155

39. Rönmark P, Jagorstrand B, Safioti G, Menon S, Bjermer L. Comparison of correct technique and preference for Spiromax ${ }^{\mathbb{R}}$, Easyhaler $^{\circledR}$ and Turbuhaler ${ }^{\circledR}$ : a single-site, single-visit, crossover study in inhaler-naïve adult volunteers. Eur Clin Respir J. 2018;5 (1):1529536. doi:10.1080/20018525.2018.1529536

40. Chapman KR, Fogarty CM, Peckitt C, et al. Delivery characteristics and patients' handling of two single-dose dry-powder inhalers used in COPD. Int J Chron Obstruct Pulmon Dis. 2011;6:353-363.

41. Takaku Y, Kurashima K, Ohta C, et al. How many instructions are required to correct inhalation errors in patients with asthma and chronic obstructive pulmonary disease? Respir Med. 2017;123:110-115. doi:10.1016/j.rmed.2016.12.012

42. Schulte M, Osseiran K, Betz R, et al. Handling of and preferences for available dry powder inhaler systems by patients with asthma and COPD. J Aerosol Med Pulm Drug Deliv. 2008;21(4):321-328. doi:10.1089/jamp.2007.0634

43. Chorão P, Pereira AM, Fonseca JA. Inhaler devices in asthma and COPD-an assessment of inhaler technique and patient preferences. Respir Med. 2014;108(7):968-975. doi:10.1016/j.rmed.2014.04.019

44. Kawamatawong T, Khiawwan S, Pornsuriyasak P. Peak inspiratory flow rate measurement by using In-Check DIAL for the different inhaler devices in elderly with obstructive airway diseases. J Asthma Allergy. 2017;10:17-21. doi:10.2147/JAA.S127580 


\section{Publish your work in this journal}

Patient Preference and Adherence is an international, peer-reviewed, open access journal that focusing on the growing importance of patient preference and adherence throughout the therapeutic continuum. Patient satisfaction, acceptability, quality of life, compliance, persistence and their role in developing new therapeutic modalities and compounds to optimize clinical outcomes for existing disease states are major areas of interest for the journal. This journal has been accepted for indexing on PubMed Central. The manuscript management system is completely online and includes a very quick and fair peer-review system, which is all easy to use. Visit http:// www.dovepress.com/testimonials.php to read real quotes from published authors. 